\title{
Translational Value of Exercise in Routine Care Following Hematopoietic Stem Cell Transplantation: A Retrospective Analysis
}

\section{Sarah Marvin ( $\nabla$ sarah.marvin@sydney.edu.au )}

The University of Sydney https://orcid.org/0000-0003-4343-2543

\section{Lois Ross}

University of Bath Department for Health

Jasmine Yee

The University of Sydney

Shelley Kay

Chris O'Brien Lifehouse

Judith Lacey

Chris O'Brien Lifehouse

Kate Edwards

The University of Sydney

\section{Research Article}

Keywords: hematologic neoplasm, hematopoietic stem cell transplantation, physical activity, fitness, fatigue, quality of life

Posted Date: September 23rd, 2021

DOl: https://doi.org/10.21203/rs.3.rs-824888/v1

License: (9) This work is licensed under a Creative Commons Attribution 4.0 International License. Read Full License 


\section{Abstract}

Purpose: Exercise is an effective adjuvant therapy to address many of the symptoms experienced by Hematopoietic Stem Cell Transplant (HSCT) recipients. However, there is little translational research examining meaningful clinical effects. A retrospective analysis of a community-embedded exercise program based at a large urban comprehensive cancer hospital was conducted, with the aim of establishing the translational value of exercise in a clinical setting. A secondary aim was to determine the impact of baseline function on exercise response.

Methods: The Living Well Program is an evidence-based program supervised by Accredited Exercise Physiologists, delivered through the Chris O'Brien Lifehouse. HSCT recipients are prescribed individualised, once-weekly 1 -hour aerobic, resistance and balance training. Changes in physical function (6-minute walk distance, strength, and balance), fatigue, and quality of life measures from baseline to post-intervention were analysed, and also assessed in relation to session attendance. Participants were then stratified as low- or high-function for each measure of physical function.

Results: Data from 48 participants (male $n=27$, age $=54.3 \pm 11.7-y e a r s$ ) was included in the analysis. Significant improvements were found for all outcome measures, with improvements exceeding minimal clinically important differences for 6-minute walk distance (6MWD) and 30-second sit-to-stand. Greater session attendance correlated with improvements in 6MWD and strength outcomes. Exercise response was greater among those with lower baseline scores for 6MWD only $(p<0.001)$.

Conclusions: An existing exercise program embedded in cancer care was successful in eliciting improvements that are both significant and clinically relevant. Further investigations into key factors that influence the efficacy of these programs are required.

\section{Introduction}

Haematological malignancies are becoming increasing prevalent in Australia, with the number of Australians diagnosed rising by $38 \%$ over the past decade [1]. Hematopoietic Stem Cell Transplantation (HSCT) is a common treatment for haematological malignancies. Although beneficial in improving survival rates, HSCT is associated with complications such as infections, graft-versus-host disease, muscle toxicity, significant functional decline, and cancer-related fatigue $[2,3]$.

HSCT is accompanied by debilitating and persistent functional limitations and physical deconditioning $[3,4]$. Prior to HSCT, individuals with haematological cancers typically present with significantly poorer exercise capacity and muscle strength compared to sex- and age-matched controls [5]. Deconditioning is then exacerbated as a consequence of extended periods of hospitalisation following HSCT. Without targeted intervention, the acute functional decline occurring in the first 6-months post-transplant are often not regained within 5-years [5, 6]. Fatigue is also a considerable concern. Up to $90 \%$ of recipients report high levels of fatigue in the acute post-HSCT period [7] and $41 \%$ experience severe fatigue during the first 
5-years [3]. These factors contribute to a reduced quality of life (QoL) and ability to perform daily tasks in this cohort [8].

As a powerful adjunct therapy, exercise has been shown to address physiological and psychological consequences of HSCT. Evidenced in a 2013 meta-analysis [9], exercise across multiple treatment timings produces significant, moderate effects for cardiorespiratory fitness, lower body strength, and fatigue. Small but significant effects for upper body strength and QoL have also been demonstrated. However, evidence for exercise initiated post-HSCT is mixed. Individual controlled trials confirm the benefit of commencing exercise in the weeks to months following HSCT, with significant improvements seen for cardiorespiratory fitness and muscle strength $[8,10,11]$. It is worth noting that with the exception of QoL, a more recent meta-analysis did not support these findings [12]; however, these conclusions are limited by the small sample size, stringency of inclusion criteria, and the potential for bias associated with the medium methodological quality of studies pooled for analysis. The efficacy of exercise programs for improving grip strength and sit-to-stand (STS) is also mixed across individual RCTs [8, 11, 13], and no known meta-analyses are available. Further research is therefore required to enhance understandings of the benefits of exercise exclusive to post-HSCT settings.

Although individuals are reported to respond positively to exercise post-HSCT, the extent to which baseline function impacts this response has not been well-established in an HSCT cohort. Among other populations, greater responses to exercise are known to be associated with poorer performance at baseline [14-16]. This is likely due to a ceiling effect limiting the degree of improvement possible among those with higher baseline scores. Therefore, less deconditioned individuals likely require a greater volume or intensity of exercise to elicit the same level of benefit [17]. A recent meta-analysis of posttreatment exercise among individuals with cancer explored this relationship [18]. Baseline strength was shown to significantly moderate the response to exercise, whilst improvements in aerobic fitness did not differ according to baseline level. However, the ability to generalise these findings to HSCT-specific contexts is impaired due to the inclusion of multiple cancer and treatment types. Only one known study has explored this concept among HSCT recipients [17], whereby participants with low baseline scores demonstrated a significantly greater response to exercise. These participants did not undergo the same degree of deconditioning as those with high baseline scores, with this functional decline attenuated for three of the five physical outcomes. However, the initiation of exercise and stratification of participants pre-HSCT limits the generalisability of the findings to all HSCT contexts, thereby necessitating similar investigations in exclusively post-HSCT settings.

Despite the recognised benefits, the majority of Australians with cancer fail to meet recommended exercise guidelines [19], with safety concerns and poor access to facilities commonly precluding participation [20,21]. Embedding exercise into routine cancer care may be an effective strategy to overcome such barriers, as supported by a recent position statement from the Clinical Oncology Society of Australia (COSA) [19]. However, as exercise is rarely integrated with HSCT-care, it is unknown whether the benefits seen in controlled settings translate into 'real world' programs. 
The primary aim of this retrospective analysis was to evaluate a community-embedded outpatient exercise program for individuals following HSCT, and to assess the effectiveness of exercise in a translational setting. The secondary aim was to determine the extent to which baseline physical function impacts exercise response.

\section{Methods}

\section{Participants}

This study was a retrospective analysis of data collected through The Living Well program at Chris O'Brien Lifehouse Comprehensive Cancer Hospital (Sydney, Australia) in the supportive care and integrative oncology outpatient department. Individuals were referred to the program by their haematologist, nurse or general practitioner following HSCT. Inclusion criteria for the program included: aged $>18$ years, specialist referral following hematopoietic stem cell transplant, haemoglobin $>6.5 \mathrm{dL}$, platelets $>15 \times 10^{9} / \mathrm{L}$, capable of walking $\geq 100 \mathrm{~m}$, able to give informed consent, and willing and able to comply with program requirements. Exclusion criteria included: Eastern Cooperative Oncology Group (ECOG) performance status $\geq 3$ or Karnofsky score $<60$, inability to read and understand English, and presence of concurrent illness or symptoms that precluded safe exercise participation. Ethical approval, with waiver of consent, was granted by the Sydney Local Health District (RPAH zone) Human Research Ethics Committee [X17-0147 \& LNR/17/RPAH/2179.47/AUG19].

The Living Well Program

The Living Well program is a multi-modal rehabilitation program for HSCT recipients. This analysis includes people $(\mathrm{N}=48)$ who participated in the program between July 2014 and June 2019. Participants were initially fee paying and prescribed a once weekly hospital outpatient-based individualised exercise program comprising progressive aerobic, resistance and balance training, delivered over an 8-week period (maximum 8 sessions). From July 2017 to June 2019, with participation free of charge due to a philanthropic donation, the restriction on maximum number of sessions was removed. One-hour sessions were conducted in a group setting and supervised by an Accredited Exercise Physiologist. Moderate intensity aerobic exercise was monitored by rate of perceived exertion (RPE), and prescribed using treadmill or cycle ergometer (upright, recumbent or arm). Resistance training intensity was prescribed based on 1 repetition maximum (1RM) testing conducted at baseline where appropriate. Participants performed 2 sets of 12 repetitions at a perceived exertion equivalent to an intensity of $60-70 \% 1 \mathrm{RM}$ during weeks $1-3$. This was increased $3 \times 10$ at 75\% 1RM (weeks $4-6$ ) and $4 \times 8$ at $80 \% 1 \mathrm{RM}$ (weeks 7 and beyond). Exercises included leg press, seated row, bicep curls, triceps dips/extensions, TRX squats, latissimus dorsi pulldowns, and hip and trunk stability. Progressive balance training was delivered using tandem walking, single-leg ball throwing, and unsteady surface standing. Support sessions were provided at the conclusion of exercise sessions; facilitated by dieticians, psychologists or yoga instructors. Participants also received 4-6 sessions of evidence-based complementary therapies in the form of oncology massage, reflexology or acupuncture according to need and preference. These therapies were 
provided by credentialed practitioners of the supportive cancer and integrative oncology outpatient department in which the study was conducted.

\section{Protocol}

Outcomes were assessed prior to the intervention (baseline) and following the final exercise session (post-intervention). Measurements of physical function and patient-reported outcomes were obtained.

\section{Outcome measures}

Physical function The distance achieved in the six-minute walk test (6MWD) was used as an indicator of functional exercise capacity and cardiorespiratory fitness [22]. Upper and lower body strength was assessed using 1 repetition maximum (1RM) testing for seated row and leg press, respectively. The 30second sit-to-stand test (30s-STS) was used to assess lower limb functional strength and endurance [23]. Participants were instructed to perform as many repetitions as possible in 30-seconds without the use of the upper limbs. Grip strength was assessed using a hand-held dynamometer (SAEHAN-SH5001 (Glanford Electronics Ltd, Scunthorpe, United Kingdom) or Deyard EH101 (Deyard tech)). The same device was used at baseline and post-intervention for each participant. for consistency. The best of three attempts was recorded for both the left and right hands, with the average of the two used for analysis. This measurement is widely considered an indicator of health status and predictor of future mortality and disability [24]. Static balance was assessed through time (in seconds) participants were able to maintain balance on one leg.

Patient-reported outcomes The Brief Fatigue Inventory $(\mathrm{BFI})$ is a simple and rapid means of evaluating daily fatigue, validated for use among individuals with cancer [25]. A global fatigue score was obtained by averaging the 9-items of the BFI, whereby a higher score indicates more significant fatigue. QoL was assessed through the self-reported Functional Assessment of Cancer Therapy - Bone Marrow Transplantation (FACT-BMT) questionnaire, which was developed and validated for use with HSCT recipients [26]. Higher scores indicate greater QoL.

Statistical Analysis

Data are expressed as means \pm standard deviation (s.d) and significance set at $p \leq 0.05$, unless otherwise stated. Descriptive statistics were used for participant demographics. Percentage change from baseline to post-intervention was calculated for all outcomes. Following tests for normality, the overall effect of the program was assessed using paired sample t-tests or its non-parametric equivalent (Wilcoxon signedrank test) to detect differences between baseline and post-intervention values. The relationship between changes in outcome measures and the number of exercise sessions attended was determined using Person's correlation or its non-parametric equivalent (Spearman Rank order correlation). Correlations are classified as weak $(r=0.1)$, moderate $(r=0.4)$ and strong $(r \geq 0.7)$ [27].

Participants were stratified into low- and high-function groups for each physical function measure according to baseline scores. It was not possible to differentiate participants according to predicted 
norms as utilised in similar research $[17,28]$ as the majority fell below age- and gender-matched normative values for 6MWD, leg press, grip strength, 30s-STS and balance [29-31]. A median split was instead used to distinguish groups, with $<$ median scores categorised as low-function and $\geq$ median scores as high-function [32]. Repeated measures ANOVAs (time \& group x time) - or Mann Whitney U tests for non-parametric data - were conducted for each outcome to examine differences in exercise response between groups.

Due to the small sample size for each outcome, Hedge's $\mathrm{g}(\mathrm{g})$ was used to indicate the magnitude of effect. Small, medium and large effect sizes are defined as $0.2,0.5$ and 0.8 respectively [33]. IBM SPSS Statistics for Macintosh Version 26 (IBM Corp., Armonk, N.Y., USA) was used for data analysis.

\section{Results}

Forty-eight participants (male $56 \%$, aged $54.3 \pm 11.7$ years) were included from an original sample of 82 (Table 1). Myeloma was the most common cancer type of those included (56.3\%), and the majority of participants (58.3\%) had autologous transplants. These participants were included due to the presence of complete baseline and post-intervention data for at least one outcome measure. Data from 34 participants was excluded, with reasons for missing data including bone disease, technical faults with equipment, acute injuries or pain at time of assessment, and difficulties with scheduling. Participants were on average $76 \pm 45$ days post-transplant at baseline.

Table 1: Participant characteristics at baseline 
Included Participants

$(\mathrm{N}=48)$

$54.3 \pm 11.7$

$76.0 \pm 45.0$
Excluded Participants

$(\mathrm{N}=34)$

$52.7 \pm 14.0$

$126.0 \pm 177.0$

(days; mean \pm s.d)

Number Percentage Number

(\%)

27

21

56.2

43.8

14

20

58.8

Cancer Type

Myeloma

27

56.3

9

26.5

Leukemia

11

22.9

5

24.7

Hodgkin Lymphoma

0

Non-Hodgkin Lymphoma

Other

Unknown

Transplant Type

\begin{tabular}{l} 
Autologous \\
\hline Allogeneic \\
\hline Unknown \\
$\begin{array}{l}\text { Participation Before / After Philanthropic } \\
\text { Donation }\end{array}$ \\
\hline
\end{tabular}

Before

39

81.3

6

17.6

After

9

18.7

28

82.4

Table 2 presents the overall effect of the program on outcome measures. Significant improvements were demonstrated for all functional measures $(p \leq 0.05)$, with moderate effects seen for 6MWD and 30s-STS $(g \geq 0.5)$. Significant effects were also observed for physical activity, fatigue and overall QoL, in addition to social wellbeing, functional wellbeing and bone marrow transplant subscales $(p \leq 0.05)$.

Table 2: Change in physical function and patient-reported outcomes from baseline to post-intervention 


$\begin{array}{llllllll}\begin{array}{l}\text { Outcome } \\ \text { Measure }\end{array} & \text { N } & \text { Baseline } & \begin{array}{l}\text { Post- } \\ \text { intervention }\end{array} & \text { Change } & \begin{array}{l}\% \\ \text { change }\end{array} & \begin{array}{l}\text { Effect } \\ \text { Size }\end{array} & \text { p-value } \\ & \text { Mean } \pm \text { s.d } & \text { Mean } \pm \text { s.d } & \text { Mean } \pm \text { s.d } & \text { Mean } & \begin{array}{l}\text { Hedges } \\ \text { G }\end{array} & & \end{array}$

\section{Physical \\ function}

\begin{tabular}{|c|c|c|c|c|c|c|c|}
\hline 6MWD (m) & 32 & $418.8 \pm 98.4$ & $497.6 \pm 82.0$ & $78.8 \pm 48.2$ & 18.8 & 0.79 & $<0.001^{*}$ \\
\hline $\begin{array}{l}\text { Seated Row } \\
\text { 1RM }(\mathrm{kg})\end{array}$ & 18 & $33.2 \pm 15.0$ & $40.6 \pm 18.0$ & $7.4 \pm 9.7$ & 22.2 & 0.46 & $<0.001^{*}$ \\
\hline $\begin{array}{l}\text { Leg Press 1RM } \\
(\mathrm{kg})\end{array}$ & 21 & $59.3 \pm 37.4$ & $73.2 \pm 37.9$ & $13.9 \pm 11.5$ & 23.5 & 0.37 & $<0.001 *$ \\
\hline 30s-STS (reps) & 20 & $12.0 \pm 3.4$ & $14.9 \pm 5.0$ & $3.0 \pm 2.9$ & 24.7 & 0.54 & $<0.001^{*}$ \\
\hline $\begin{array}{l}\text { Grip Strength } \\
(\mathrm{kg})^{\S}\end{array}$ & 24 & $28.7 \pm 12.5$ & $30.6 \pm 11.5$ & $1.9 \pm 4.0$ & 6.6 & 0.14 & $0.03 *$ \\
\hline Balance (secs) & 25 & $34.3 \pm 22.0$ & $42.8 \pm 18.7$ & $8.5 \pm 10.9$ & 24.8 & 0.38 & $<0.001 *$ \\
\hline
\end{tabular}

\section{Patient-reported outcomes}

$\begin{array}{llllllll}\mathrm{BFI} & 28 & 4.6 \pm 1.9 & 3.4 \pm 2.2 & -1.2 \pm 2.5 & -25.7 & 0.22 & <0.001^{*}\end{array}$

\section{FACT-BMT}

$\begin{array}{llllllll}\text { Total Score } & 15 & 97.5 \pm 16.4 & 105.5 \pm 16.2 & 8.1 \pm 10.6 & 8.3 & 0.47 & 0.01 \text { * }\end{array}$

\section{Wellbeing \\ domains}

\begin{tabular}{lccccccc}
\hline Physical & 21 & $19.0 \pm 6.2$ & $21.3 \pm 4.9$ & $2.3 \pm 7.1$ & 12.1 & 0.30 & 0.12 \\
\hline Social & 22 & $21.7 \pm 5.6$ & $23.1 \pm 4.6$ & $1.4 \pm 1.5$ & 6.3 & 0.19 & $0.02^{\star}$ \\
\hline Emotional & 15 & $19.6 \pm 2.7$ & $19.5 \pm 2.5$ & $-0.1 \pm 2.3$ & -0.4 & 0.02 & 0.86 \\
\hline Functional $\S$ & 16 & $17.1 \pm 4.9$ & $19.7 \pm 5.2$ & $2.5 \pm 4.6$ & 14.8 & 0.41 & $0.04^{\star}$ \\
\hline BMT $\S$ & 16 & $22.2 \pm 4.4$ & $24.0 \pm 4.4$ & $1.8 \pm 3.1$ & 8.1 & 0.31 & $0.04^{\star}$
\end{tabular}

* significant at $p<0.05$; \#negative change denotes improvement; §analysis using paired samples t-test; 6MWD: six-minute walk distance; 1RM: 1-reptition maximum; 30s-STS: 30-second sit-to-stand; BFI:

Brief Fatigue Inventory; FACT-BMT: Functional Assessment of Cancer Therapy - Bone Marrow Transplant

A moderate, positive correlation was observed between the number of exercise sessions attended and change in leg press 1RM $(r=0.41)$, whilst weak correlations were observed for 6MWD $(r=0.17)$, grip strength $(r=0.32)$ and seated row 1RM $(r=0.37)$. No other relationships with session attendance were identified. 
The extent to which baseline function impacted exercise response was less consistent (Table 3). A statistically significant difference in exercise response between groups was only observed for 6MWD ( $p<$ 0.01). Despite this, percentage change from baseline to post-intervention favoured the low-function. Greater effect sizes were also observed within this group for most measures, with large effects seen for $6 \mathrm{MWD}$, seated row $1 \mathrm{RM}$, leg press $1 \mathrm{RM}$, and balance $(\mathrm{g}>0.80)$. For $6 \mathrm{MWD}$, improvements in both low- $(+$ $107.9 \mathrm{~m})$ and high-function $(+49.6 \mathrm{~m})$ groups exceeded the minimal clinically important difference (MCID) value of 14-30.5m [34]. Improvements in 30s-STS for both groups (+ 2.5-reps; +3.4-reps) were also within the MCID of 2-3 repetitions $[35,36]$.

Table 3: Comparison of change in physical function in low- and high-function groups from baseline to post-intervention 


\begin{tabular}{|c|c|c|c|c|c|c|}
\hline Variable & $\mathbf{N}$ & $\begin{array}{l}\text { Baseline } \\
\text { Mean } \pm \text { s.d }\end{array}$ & $\begin{array}{l}\text { Post- } \\
\text { intervention } \\
\text { Mean } \pm \text { s.d }\end{array}$ & $\begin{array}{l}\text { Change } \\
\text { Mean } \pm \text { s.d }\end{array}$ & $\begin{array}{l}\% \\
\text { change } \\
\text { Mean }\end{array}$ & $\begin{array}{l}\text { Effect } \\
\text { Size } \\
\text { Hedge's } \\
\text { G }\end{array}$ \\
\hline
\end{tabular}

6MWD (m) $<0.001^{*}$

$\begin{array}{lcccccc}\text { Low-function } & 16 & 342.5 \pm 63.3 & 450.4 \pm 67.2 & 107.9 \pm 42.9 & 31.5 & 1.67 \\ \text { High-function } & 16 & 495.1 \pm 60.0 & 544.7 \pm 68.2 & 49.6 \pm 33.8 & 10.0 & 0.81\end{array}$

Seated Row

$1 \mathrm{RM}(\mathrm{kg})$

\begin{tabular}{lllllll} 
Low-function & 9 & $20.8 \pm 5.4$ & $27.5 \pm 6.5$ & $6.7 \pm 2.6$ & 32.2 & 1.21 \\
\hline High-function & 9 & $45.6 \pm 10.4$ & $53.6 \pm 16.3$ & $8.1 \pm 13.1$ & 17.8 & 0.59
\end{tabular}

Leg Press 1RM

(kg)

0.88

0.44

$\begin{array}{lllllll}\text { Low-function } & 10 & 31.0 \pm 11.5 & 41.3 \pm 13.1 & 10.3 \pm 8.1 & 33.2 & 0.84 \\ \text { High-function } & 11 & 85.0 \pm 33.8 & 102.3 \pm 27.8 & 17.3 \pm 12.6 & 20.4 & 0.56\end{array}$

30s-STS (reps)

0.88

$\begin{array}{lllllll}\text { Low-function } & 10 & 9.5 \pm 1.8 & 12.0 \pm 2.4 & 2.5 \pm 2.2 & 26.3 & 0.76 \\ \text { High-function } & 10 & 14.4 \pm 2.7 & 17.8 \pm 5.3 & 3.4 \pm 3.4 & 23.6 & 0.85\end{array}$

Grip Strength

$(\mathrm{kg})^{\S}$

$\begin{array}{llllllll}\text { Low-function } & 12 & 18.1 \pm 4.2 & 21.3 \pm 5.3 & 3.2 \pm 2.1 & 17.4 & 0.60 & \begin{array}{l}0.13 \\ \text { (Group }\end{array} \\ \text { High-function } & 12 & 39.3 \pm 8.0 & 39.9 \pm 7.5 & 0.7 \pm 5.1 & 1.7 & 0.07 & \text { x Time) }\end{array}$

Balance (secs)

0.11

$\begin{array}{lllllll}\text { Low-function } & 12 & 14.4 \pm 10.0 & 25.6 \pm 11.0 & 11.3 \pm 12.7 & 78.2 & 1.05 \\ \text { High-function } & 13 & 52.7 \pm 10.4 & 58.7 \pm 4.7 & 6.0 \pm 8.8 & 11.3 & 0.55\end{array}$

* significant at $p<0.05 ; \S$ analysis using repeated measures ANOVA; 6MWD: six-minute walk distance; 1RM: 1-reptition maximum; 30s-STS: 30-second sit-to-stand;

\section{Discussion}

This study demonstrated the overall effectiveness of an exercise program embedded in cancer care and evaluated the extent to which baseline function impacted the response to exercise following HSCT. The success of the program in improving all measures of physical function is important given the nature of the program provision. These improvements are not surprising as they are in line with much of the 
literature of controlled trials, confirming the benefits of exercise for 6MWD and cardiorespiratory fitness in HSCT recipients [8-11, 17]. Recent evidence suggests nearly half of HSCT recipients exhibit moderate to severe impairments in exercise capacity at one-year post-HSCT [28], thus demonstrating the important role for translation of exercise provision into care in this period. It is of note that meaningful relationships were observed between session attendance and improvements in 6MWD and maximal strength (leg press $1 R M$, seated row 1RM), suggesting session adherence was an important moderator of improvements in these outcomes. Balance also improved in response to the intervention, consistent with evidence from a systematic review among cancer survivors with balance impairments [37]. Furthermore, whilst the efficacy of interventions is commonly quantified using statistical measures, the use of minimal clinically important difference (MCID) values has been proposed as a key evaluator of translational research [38]. Despite differences in responsiveness to exercise according to baseline function, improvements in 6MWD and 30s-STS were both statistically and clinically significant for the two groups, with average improvements exceeding MCIDs for these measures [34-36]. Overall, the program was efficacious for the cohort in addressing the marked treatment related reductions in exercise capacity, strength and balance, which subsequently negatively affect QoL and interfere with daily function $[5,8]$.

Cancer-related fatigue has a complex aetiology involving inflammation, disease, treatment, demographic and psychological features [39]. Although the mechanisms by which exercise ameliorates fatigue are not well understood, the significant reduction in fatigue seen in the current study supports available literature among HSCT recipients. Whilst promising, post-intervention fatigue levels remained elevated, nearing moderate [25]. However, this is not unexpected as increased levels of fatigue commonly persist in the years following HSCT [3]. It is also noted that the recommended approach to post-treatment cancerrelated fatigue is multimodal [42], and as such, the inclusion of evidence-informed complementary therapies may have contributed to the perceived improvement in fatigue.

The efficacy of the program on QoL varied between subscales, with no improvements evidenced in emotional wellbeing and non-significant improvements observed in physical wellbeing. Evidence for improvements in specific subsets of QoL among HSCT recipients is mixed $[4,13,43]$, however the significant improvement in overall QoL is consistent with meta-analyses $[9,12]$. With QoL negatively impacted by physiological and psychological consequences of HSCT, the significant improvement in overall QoL and across 3-subscales within the present study, albeit small, is promising.

One variable of interest in evaluating the feasibility of programs embedded in cancer care is the financial burden placed on patients. The relationship between financial support or investment and program attendance is vital in the implementation of exercise in cancer care, especially given the prolonged treatments and financial toxicity associated with haematological malignancies. Correlations between session attendance and magnitude improvement were observed for 4 measures. However few conclusions can be drawn due to the restrictions on session attendance placed upon the majority of participants included in this analysis who attended the program prior to the philanthropic donation. Programs of longer duration or without restrictions on number of permissible sessions should be studied to improve understandings of associations between session attendance and magnitude of improvement. 
The impact of baseline function on exercise response was inconsistent. The inverse relationship between 6MWD at baseline and responsiveness to exercise is consistent with prior research in an HSCT setting [17]. However, whilst the ability to draw accurate comparisons with similar research is limited due to timing of exercise around HSCT and measurements use to assess outcomes, the absence of statistically significant differences between groups for remaining outcomes contrasts such research [17]. This disparity may be due to differences in extent of deconditioning at baseline. Participants in the current study were more deconditioned than expected based upon existing literature $[8,10,11]$, which influenced the method used to stratify participants. Whilst low- and high-function was used to describe the groups, the overwhelming majority would be classified as low-function based on norms [29-31]. Hence, it is likely a ceiling effect was not present within this sample, thus contributing to the absence of significant differences between groups for most outcomes.

Although the absolute change in physical and functional measures was similar between groups for all outcomes except 6MWD, improvements in proportion to baseline values (percentage change) were consistently higher among the low-function group by virtue of their poorer scores at baseline. Larger effect sizes were also observed within this group for most outcomes. Therefore, despite failing to reach statistical significance for five of the six outcomes, differences in exercise response according to baseline function were present. Understanding such differences is vital in informing realistic goal setting and prescription. Future research should investigate the effect of varying exercise volume and intensity according to baseline function, with suggestions a greater exercise prescription may be necessary for those with higher baseline scores to elicit comparable benefits [17].

Furthermore, this was a multimodal exercise-based program that also included access to evidenceinformed complementary medicine interventions and lifestyle education. Although not included in this analysis, future research would benefit from further examination of the impact of patient uptake of these complementary therapies due to understandings of the benefits of an integrative approach to cancer care [42].

Various limitations must be considered in interpreting these findings. Large amounts of data were unaccounted for, which reduced the sample size available for analysis. Although not unexpected given the nature of the retrospective data acquisition, future research would benefit from more defined data collection procedures. The pre-post design also presents a potential for the results to exaggerate a true effect, and without a controlled comparison, the extent to which improvements within the present study are attributable to the prescribed exercise remains open to investigation. As the ethics of conducting an RCT by means of depriving a control group of a recognised standard of care remain the subject of much debate, future research should instead focus on achieving an optimal program design by identifying characteristics of this population that interact with exercise training variables. Whilst evidence specific to HSCT is still in its infancy, greater levels of physical activity are associated with lower mortality risk across other cancer types [44]. As such, future translational research should investigate the potential impact of the program on improved self-efficacy and increased physical activity beyond supervised sessions as measured through validated assessment tools. Despite these limitations, the significant 
improvements were obtained from a 'real world' clinical setting. This suggests the improvements observed in specifically designed clinical trials can be translated into practice, thus signifying the efficacy of an existing program embedded in cancer care.

\section{Conclusion}

The Living Well Program was successful in improving physical function, fatigue and QoL post-HSCT. Exercise response differed according to baseline function for measures of physical function, however only reached significance in 6MWD. This study supports the clinically meaningful efficacy of a real-world program embedded in cancer care and confirms that implementation of tailored exercise programs will likely benefit HSCT recipients in their recovery.

\section{Declarations}

Funding: No funding was received to assist with the preparation of this manuscript.

Conflicts of interest: Authors S. Marvin, L. Ross, J. Yee, and K. Edwards have no financial or non-financial interests to disclose. Authors S. Kay and J. Lacey are employed by the institution at which the study took place.

Availability of data and material: On request.

Code availability: Not applicable.

Ethics approval: Ethical approval, with waiver of consent, was granted by the Sydney Local Health District (RPAH zone) Human Research Ethics Committee [X17-0147 \& LNR/17/RPAH/2179.47/ AUG19].

Consent to participate: Consent to the program was provided by each participant.

Consent for publication: Waiver of consent provided for de-identified data granted by ethics.

Author contributions: All authors contributed to the final manuscript. KE and SK conceived the study, SM and LR performed the data analysis and drafted the manuscript in consultation with JY, SK, JL and KE who contributed to the reviewing and editing of manuscript.

Acknowledgments: The authors would like to acknowledge the staff and patients at the Chris O'Brien Lifehouse for their contributions to data collection.

\section{References}

1. Australian Institute of Health and W (2020) Cancer Data in Australia 2020. AlHW, Canberra

2. Copelan EA (2006) Hematopoietic stem-cell transplantation. N Engl J Med 354(17):1813-1826. doi:10.1056/NEJMra052638 
3. Gielissen MF, Schattenberg AV, Verhagen CA, Rinkes MJ, Bremmers ME, Bleijenberg G (2007) Experience of severe fatigue in long-term survivors of stem cell transplantation. Bone marrow transplantation 39(10):595-603. doi:10.1038/sj.bmt.1705624

4. Wilson RW, Jacobsen PB, Fields KK (2005) Pilot study of a home-based aerobic exercise program for sedentary cancer survivors treated with hematopoietic stem cell transplantation. Bone marrow transplantation 35(7):721-727. doi:10.1038/sj.bmt.1704815

5. Morishita S, Kaida K, Tanaka T, Itani Y, Ikegame K, Okada M, Ishii S, Kodama N, Ogawa H, Domen K (2012) Prevalence of sarcopenia and relevance of body composition, physiological function, fatigue, and health-related quality of life in patients before allogeneic hematopoietic stem cell transplantation. Supportive care in cancer: official journal of the Multinational Association of Supportive Care in Cancer 20(12):3161-3168. doi:10.1007/s00520-012-1460-5

6. Kyle UG, Chalandon Y, Miralbell R, Karsegard VL, Hans D, Trombetti A, Rizzoli R, Helg C, Pichard C (2005) Longitudinal follow-up of body composition in hematopoietic stem cell transplant patients. Bone marrow transplantation 35(12):1171-1177. doi:10.1038/sj.bmt.1704996

7. Bevans MF, Mitchell SA, Marden S (2008) The symptom experience in the first 100 days following allogeneic hematopoietic stem cell transplantation (HSCT). Supportive care in cancer: official journal of the Multinational Association of Supportive Care in Cancer 16(11):1243-1254. doi:10.1007/s00520-008-0420-6

8. Hayes SC, Davies PS, Parker TW, Bashford J, Green A (2004) Role of a mixed type, moderate intensity exercise programme after peripheral blood stem cell transplantation. $\mathrm{Br} J$ Sports Med 38(3):304309. doi:10.1136/bjsm.2002.003632 discussion 309.

9. Persoon S, Kersten MJ, van der Weiden K, Buffart LM, Nollet F, Brug J, Chinapaw MJ (2013) Effects of exercise in patients treated with stem cell transplantation for a hematologic malignancy: a systematic review and meta-analysis. Cancer treatment reviews 39(6):682-690. doi:10.1016/j.ctrv.2013.01.001

10. Shelton ML, Lee JQ, Morris GS, Massey PR, Kendall DG, Munsell MF, Anderson KO, Simmonds MJ, Giralt SA (2009) A randomized control trial of a supervised versus a self-directed exercise program for allogeneic stem cell transplant patients. Psycho-oncology 18(4):353-359. doi:10.1002/pon.1505

11. Knols RH, de Bruin ED, Uebelhart D, Aufdemkampe G, Schanz U, Stenner-Liewen F, Hitz F, Taverna C, Aaronson NK (2011) Effects of an outpatient physical exercise program on hematopoietic stem-cell transplantation recipients: a randomized clinical trial. Bone marrow transplantation 46(9):12451255. doi:10.1038/bmt.2010.288

12. Liang Y, Zhou M, Wang F, Wu Z (2018) Exercise for physical fitness, fatigue and quality of life of patients undergoing hematopoietic stem cell transplantation: a meta-analysis of randomized controlled trials. Jpn J Clin Oncol 48(12):1046-1057. doi:10.1093/jjco/hyy144

13. Persoon S, Chin AMJM, Buffart LM, Liu RDK, Wijermans P, Koene HR, Minnema MC, Lugtenburg PJ, Marijt EWA, Brug J, Nollet F, Kersten MJ (2017) Randomized controlled trial on the effects of a supervised high intensity exercise program in patients with a hematologic malignancy treated with 
autologous stem cell transplantation: Results from the EXIST study. PloS one 12(7):e0181313. doi:10.1371/journal.pone.0181313

14. Laddu D, Ozemek C, Lamb B, Hauer T, Aggarwal S, Stone JA, Arena R, Martin BJ (2018) Factors Associated With Cardiorespiratory Fitness at Completion of Cardiac Rehabilitation: Identification of Specific Patient Features Requiring Attention. Can J Cardiol 34(7):925-932. doi:10.1016/j.cjca.2018.03.015

15. Gruber W, Orenstein DM, Braumann KM (2011) Do responses to exercise training in cystic fibrosis depend on initial fitness level? Eur Respir J 38(6):1336-1342. doi:10.1183/09031936.00192510

16. Layne AS, Hsu FC, Blair SN, Chen SH, Dungan J, Fielding RA, Glynn NW, Hajduk AM, King AC, Manini TM, Marsh AP, Pahor M, Pellegrini CA, Buford TW (2017) Predictors of Change in Physical Function in Older Adults in Response to Long-Term, Structured Physical Activity: The LIFE Study. Arch Phys Med Rehabil 98(1):11-24.e13. doi:10.1016/j.apmr.2016.07.019

17. Wiskemann J, Kuehl R, Dreger P, Schwerdtfeger R, Huber G, Ulrich CM, Jaeger D, Bohus M (2014) Efficacy of exercise training in SCT patients-who benefits most? Bone marrow transplantation 49(3):443-448. doi:10.1038/bmt.2013.194

18. Buffart LM, Sweegers MG, May AM, Chinapaw MJ, van Vulpen JK, Newton RU, Galvão DA, Aaronson NK, Stuiver MM, Jacobsen PB, Verdonck-de Leeuw IM, Steindorf K, Irwin ML, Hayes S, Griffith KA, Lucia A, Herrero-Roman F, Mesters I, van Weert E, Knoop H, Goedendorp MM, Mutrie N, Daley AJ, McConnachie A, Bohus M, Thorsen L, Schulz KH, Short CE, James EL, Plotnikoff RC, Arbane G, Schmidt ME, Potthoff K, van Beurden M, Oldenburg HS, Sonke GS, van Harten WH, Garrod R, Schmitz KH, Winters-Stone KM, Velthuis MJ, Taaffe DR, van Mechelen W, José Kersten M, Nollet F, Wenzel J, Wiskemann J, Brug J, Courneya KS (2018) Targeting Exercise Interventions to Patients With Cancer in Need: An Individual Patient Data Meta-Analysis. J Natl Cancer Inst 110(11):1190-1200. doi:10.1093/jnci/djy161

19. Cormie P, Atkinson M, Bucci L, Cust A, Eakin E, Hayes S, McCarthy S, Murnane A, Patchell S, Adams D (2018) Clinical Oncology Society of Australia position statement on exercise in cancer care. The Medical journal of Australia 209(4):184-187

20. Blaney JM, Lowe-Strong A, Rankin-Watt J, Campbell A, Gracey JH (2013) Cancer survivors' exercise barriers, facilitators and preferences in the context of fatigue, quality of life and physical activity participation: a questionnaire-survey. Psycho-oncology 22(1):186-194. doi:10.1002/pon.2072

21. Eng L, Pringle D, Su J, Shen X, Mahler M, Niu C, Charow R, Tiessen K, Lam C, Halytskyy O, Naik H, Hon H, Irwin M, Pat V, Gonos C, Chan C, Villeneuve J, Harland L, Shani RM, Brown MC, Selby P, Howell D, Xu W, Liu G, Alibhai SMH, Jones JM (2018) Patterns, perceptions, and perceived barriers to physical activity in adult cancer survivors. Supportive care in cancer: official journal of the Multinational Association of Supportive Care in Cancer 26(11):3755-3763. doi:10.1007/s00520-018-4239-5

22. Schmidt K, Vogt L, Thiel C, Jäger E, Banzer W (2013) Validity of the six-minute walk test in cancer patients. Int J Sports Med 34(7):631-636. doi:10.1055/s-0032-1323746 
23. Jones CJ, Rikli RE, Beam WC (1999) A 30-s chair-stand test as a measure of lower body strength in community-residing older adults. Res Q Exerc Sport 70(2):113-119.

doi:10.1080/02701367.1999.10608028

24. Leong DP, Teo KK, Rangarajan S, Lopez-Jaramillo P, Avezum A Jr, Orlandini A, Seron P, Ahmed SH, Rosengren A, Kelishadi R, Rahman O, Swaminathan S, Iqbal R, Gupta R, Lear SA, Oguz A, Yusoff K, Zatonska K, Chifamba J, Igumbor E, Mohan V, Anjana RM, Gu H, Li W, Yusuf S (2015) Prognostic value of grip strength: findings from the Prospective Urban Rural Epidemiology (PURE) study. Lancet 386(9990):266-273. doi:10.1016/s0140-6736(14)62000-6

25. Mendoza TR, Wang XS, Cleeland CS, Morrissey M, Johnson BA, Wendt JK, Huber SL (1999) The rapid assessment of fatigue severity in cancer patients: use of the Brief Fatigue Inventory. Cancer 85 (5):1186-1196. doi:10.1002/(sici)1097-0142(19990301)85:5<1186::aid-cncr24>3.0.co;2-n

26. McQuellon RP, Russell GB, Cella DF, Craven BL, Brady M, Bonomi A, Hurd DD (1997) Quality of life measurement in bone marrow transplantation: development of the Functional Assessment of Cancer Therapy-Bone Marrow Transplant (FACT-BMT) scale. Bone marrow transplantation 19(4):357-368. doi:10.1038/sj.bmt.1700672

27. Dancey C, J R (2007) Statistics Without Maths for Psychology. Pearson Education

28. Dirou S, Chambellan A, Chevallier P, Germaud P, Lamirault G, Gourraud PA, Perrot B, Delasalle B, Forestier B, Guillaume T, Peterlin P, Garnier A, Magnan A, Blanc FX, Lemarchand P (2018) Deconditioning, fatigue and impaired quality of life in long-term survivors after allogeneic hematopoietic stem cell transplantation. Bone marrow transplantation 53(3):281-290. doi:10.1038/s41409-017-0057-5

29. American College of Sports M, Riebe D, Ehrman J, Liguori G, Magal M (2018) ACSM's guidelines for exercise testing and prescription

30. Rikli RE, Jones CJ (1999) Functional Fitness Normative Scores for Community-Residing Older Adults, Ages 60-94. 7 (2):162. doi:10.1123/japa.7.2.162 10.1123/japa.7.2.162 10.1123/japa.7.2.162 10.1123/japa.7.2.162

31. Springer BA, Marin R, Cyhan T, Roberts H, Gill NW (2007) Normative values for the unipedal stance test with eyes open and closed. Journal of geriatric physical therapy (2001) 30 (1):8-15. doi:10.1519/00139143-200704000-00003

32. Bouchard C, Rankinen T (2001) Individual differences in response to regular physical activity. Medicine and science in sports and exercise 33 (6 Suppl):S446-451; discussion S452-443. doi:10.1097/00005768-200106001-00013

33. Hedges L, Olkin I (1985) Statistical Methods in Meta-Analysis. Stat Med 20. doi:10.2307/1164953

34. Bohannon RW, Crouch R (2017) Minimal clinically important difference for change in 6-minute walk test distance of adults with pathology: a systematic review. Journal of evaluation in clinical practice 23(2):377-381. doi:10.1111/jep.12629

35. Zanini A, Crisafulli E, D'Andria M, Gregorini C, Cherubino F, Zampogna E, Azzola A, Spanevello A, Schiavone N, Chetta A (2019) Minimum Clinically Important Difference in 30-s Sit-to-Stand Test After 
Pulmonary Rehabilitation in Subjects With COPD. Respiratory care 64(10):1261-1269. doi:10.4187/respcare.06694

36. Lyders Johansen K, Derby Stistrup R, Skibdal Schjøtt C, Madsen J, Vinther A (2016) Absolute and Relative Reliability of the Timed 'Up \& Go' Test and '30second Chair-Stand' Test in Hospitalised Patients with Stroke. PloS one 11(10):e0165663. doi:10.1371/journal.pone.0165663

37. Duregon F, Vendramin B, Bullo V, Gobbo S, Cugusi L, Di Blasio A, Neunhaeuserer D, Zaccaria M, Bergamin M, Ermolao A (2018) Effects of exercise on cancer patients suffering chemotherapyinduced peripheral neuropathy undergoing treatment: A systematic review. Crit Rev Oncol Hematol 121:90-100. doi:10.1016/j.critrevonc.2017.11.002

38. Draak THP, de Greef BTA, Faber CG, Merkies ISJ (2019) The minimum clinically important difference: which direction to take. European journal of neurology 26(6):850-855. doi:10.1111/ene.13941

39. Ryan JL, Carroll JK, Ryan EP, Mustian KM, Fiscella K, Morrow GR (2007) Mechanisms of cancerrelated fatigue. The oncologist 12 Suppl 1:22-34. doi:10.1634/theoncologist.12-S1-22

40. Chiffelle R, Kenny K (2013) Exercise for fatigue management in hematopoietic stem cell transplantation recipients. Clin J Oncol Nurs 17(3):241-244. doi:10.1188/13.Cjon.241-244

41. Oberoi S, Robinson PD, Cataudella D, Culos-Reed SN, Davis H, Duong N, Gibson F, Götte M, Hinds P, Nijhof SL, Tomlinson D, van der Torre P, Cabral S, Dupuis LL, Sung L (2018) Physical activity reduces fatigue in patients with cancer and hematopoietic stem cell transplant recipients: A systematic review and meta-analysis of randomized trials. Crit Rev Oncol Hematol 122:52-59. doi:10.1016/j.critrevonc.2017.12.011

42. Okolo ON, Gowin K (2019) Emerging Role of Integrative Medicine in Hematologic Malignancies: a Literature Review and Update on Current Trends in Complementary Medical Practices in Hematologic Cancers. Curr Hematol Malig Rep 14(4):328-336. doi:10.1007/s11899-019-00526-8

43. Jarden M, Nelausen K, Hovgaard D, Boesen E, Adamsen L (2009) The effect of a multimodal intervention on treatment-related symptoms in patients undergoing hematopoietic stem cell transplantation: a randomized controlled trial. J Pain Symptom Manag 38(2):174-190. doi:10.1016/j.jpainsymman.2008.09.005

44. Cormie P, Zopf EM, Zhang X, Schmitz KH (2017) The Impact of Exercise on Cancer Mortality, Recurrence, and Treatment-Related Adverse Effects. Epidemiol Rev 39(1):71-92. doi:10.1093/epirev/mxx007

\section{Supplementary Files}

This is a list of supplementary files associated with this preprint. Click to download.

- BMTDATA.xIsx 